

\title{
Pesquisa e Análise do ChatterBot Dr. Remus Philius para atualizá-lo com novas tecnologias
}

\section{Pedro Henrique Bianchi ${ }^{\star}$, Marcos A. F. Borges}

\section{Resumo}

Este projeto teve como objetivo analisar a atual implementação do ChatterBot Dr. Remus Philius, um chatterbot que faz parte do Hemotion Game, a fim de verificar a necessidade, ou não, de trazê-lo para uma nova plataforma .

Palavras-chave:

ChatBot, AIML, Chatscript.

\section{Introdução}

O ChatterBot Dr. Remus Philius é um sistema especialista em hemofilia que simula a interação entre um paciente e um médico. Nele, as perguntas são feitas ao médico pela criança hemofílica e, quando há uma resposta conhecida, ela é retornada ao usuário. Este módulo do Hemotion tem como objetivo ensinar conceitos sobre hemofilia para crianças e adolescentes.

$\mathrm{Na}$ versão atual, para utilizar o Chatterbot é necessário que a criança já saiba ler e escrever pois, conforme ilustra a Figura 1 o usuário digita a pergunta na caixa de texto que fica na parte inferior da tela e a resposta é exibida no quadro branco.

Figura 1 Interface do Chatterbot

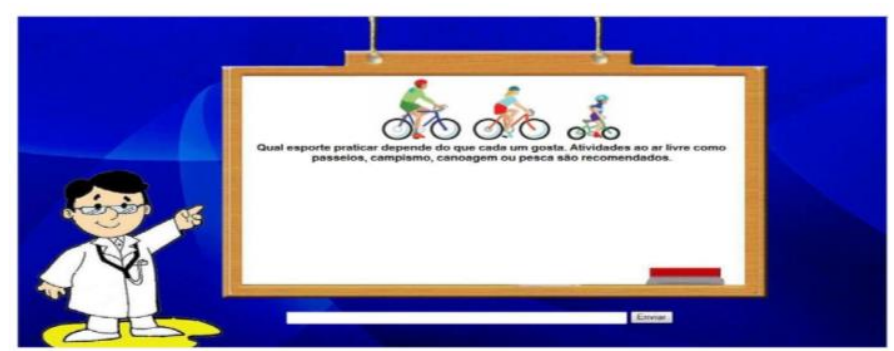

Então o intuito da pesquisa seria atualizar o ChatterBot para que ele possa interagir com os recentes frameworks de processamento de linguagem natural e assim fosse capaz de oferecer uma interface em que o usuário fale suas perguntas e ouça as respostas, sem a necessidade de digitação.

\section{Resultados e Discussão}

Chatscript (Site Oficial Chatscript, 2018) é uma combinação de Linguagem Natural e um sistema de gerenciamento de diálogos, inicialmente desenvolvido para criação de Chatbots, porém também é utilizado para diversas formas de processamento de Linguagem Natural.
O Chatscript tem como prós um forte reconhecimento de padrões, robustez, capacidade de ser flexível e eficiente ao problema que deseja atacar e também conta com uma excelente documentação e suporte disponíveis on-line. As desvantagens são que ele é mais difícil de aprender do que o AIML pois se faz necessário alguém com conhecimento de programação.

AIML (Site referência AIML, 2018), Artificial Intelligence Markup Language, é uma linguagem baseada em XML desenvolvida para criar diálogos semelhante a linguagem natural.

AIML tem como prós ser simples, pois é baseada em XML, fácil de aprender e de implementar. É possível encontrar alguns modelos de bot prontos em que, com algumas modificações, se o intuito é um chatterbot simples, se consegue adaptar ao seu uso. As desvantagens são que AIML tem um reconhecimento de padrões fraco, não sendo robusto. Se o intuito é desenvolver um chatbot elaborado, se faz necessário a criação de uma quantidade grande de categorias e regras.

\section{Conclusões}

Este relatório contempla as pesquisas e atividades desenvolvidas no período vigente da bolsa que foi iniciado em Agosto/2017 e foi interrompido ao final de Outubro/2017.

Sendo assim as conclusões se limitam à dizer que o Chatscript é a melhor escolha para chatterbots mais robustos e AIML para soluções mais simples.

MATSUNAGA, Roberta Mayumi, Desenvolvimento de um jogo educativo para crianças com hemofilia, 2013, Dissertação Mestrado.

Site oficial do Chatscript: https://sourceforge.net/projects/chatscript/ Último acesso: 19/02/2018.

Site referência AIML: https:/www.pandorabots.com/docs/aiml/aimlbasics.html

Último acesso: 20/02/2018 